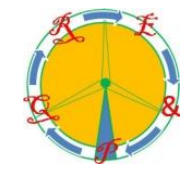

\title{
Analysis of the Influences of Changes in Gains and Time Constants in a Power Factor Regulator Using ATP-EMTP
}

\author{
M.J.B.B. Davi ${ }^{1}$, J.R.C de Almeida ${ }^{1}$, C. B. dos Santos ${ }^{1}$, F. A. M. Moura ${ }^{1}$, M. V. B. Mendonça ${ }^{1}$, J.R. Camacho ${ }^{2}$ \\ ${ }^{1}$ Universidade Federal do Triângulo Mineiro, Electrical Engineering Department, Uberaba, Minas Gerais, Brazil \\ moisesjr20@hotmail.com, julianaramosca@hotmail.com, caio.borgess@ hotmail.com, marcusmvbm@gmail.com, \\ fabricio@eletrica.uftm.edu.br
}

${ }^{2}$ Universidade Federal de Uberlândia, School of Electrical Engineering, Uberlândia, Minas Gerais, Brazil jrcamacho@ufu.br

\begin{abstract}
The objective of this study is to analyze the influence of the gains and time constants in a control system of a Power Factor Regulator. This regulator was modeled using the "TACS - Transients Analysis Control System" routine "ATPEMTP - Alternative Transients Program". This regulator is connected to a synchronous machine of an independent producer, and later, is observed the behavior of machine speed in steady state, the rms voltage and power factor is observed in the PCC (Point of Common Coupling) of the system. Finally, appropriate conclusions about the influence of the gains and time constants for the regulator power factor is conducted, seeking a system that behaves as stable as possible, taking into account the rules related to the insertion of distributed generators in the Electric System.
\end{abstract}

\section{Key words}

Distributed generation, Power Factor Regulator, Excitation Control Systems, Transient Stability, Independent Generation, Power Distribution System

\section{Nomenclature}

$\mathrm{K}_{\mathrm{a}}$ regulator gain.

$\mathrm{K}_{\mathrm{e}}$ excitation constant related $\mathrm{t} \mathrm{o}$ the excitation of the field.

$\mathrm{K}_{\mathrm{f}}$ time gain of the regulator stabilizer circuit.

$\mathrm{T}_{\mathrm{a}}$ regulator amplified time constant.

$\mathrm{T}_{\mathrm{r}}$ regulator input filter time constant.

$\mathrm{T}_{\mathrm{e}}$ the exciter time constant.

$\mathrm{T}_{\mathrm{f}}$ regulator stabilizer time constant.

$\mathrm{E}_{\mathrm{f}}$ field voltage (pu).

$S_{n}$ rated apparent power.

$\mathrm{U}_{\mathrm{n}}$ rated voltage.

$\mathrm{R}_{\mathrm{a}}$ armature resistance (pu).

$\mathrm{X}_{\mathrm{L}}$ armature leakage reactance $(\mathrm{pu})$.

$\mathrm{x}_{\mathrm{d}}$ direct axis reactance $(\mathrm{pu})$.

$\mathrm{x}_{\mathrm{q}} \quad$ quadrature axis reactance $(\mathrm{pu})$.

$\mathrm{x}_{\mathrm{d}}$ direct axis transient reactance $(\mathrm{pu})$.

$\mathrm{X}_{\mathrm{q}} \quad$ quadrature axis transient reactance $(\mathrm{pu})$.

$\mathrm{x},{ }_{\mathrm{d}}$ direct axis sub transient reactance $(\mathrm{pu})$.

$\mathrm{x}{ }^{\prime}{ }_{\mathrm{q}}$ quadrature axis sub transient reactance $(\mathrm{pu})$. $\mathrm{x}_{\mathrm{o}} \quad$ zero sequence reactance $(\mathrm{pu})$.

$\mathrm{T}_{\mathrm{d} 0}$ direct axis transient short-circuit time constant (s).

$\mathrm{T}_{\mathrm{q} 0}$ quadrature axis transient short-circuit time constant (s). $\mathrm{T}$ ' ${ }_{\mathrm{d} 0}$ direct axis sub transient short-circuit time constant (s).

$\mathrm{T}$ " ${ }_{\text {q0 }}$ quadrature axis sub transient short-circuit time constant (s).

$\mathrm{H}=$ inertia moment $\left(10^{6} . \mathrm{Kg} \cdot \mathrm{m}^{2}\right)$.

$\mathrm{P}=$ pole number

$\mathrm{f}=$ frequency $(\mathrm{Hz})$.

$\dot{\omega}=$ synchronous speed in $(\mathrm{rad} / \mathrm{s})$.

$\mathrm{G}=$ "fly ball" gain.

$\mathrm{T}_{\mathrm{fb}}=$ "fly ball" time constant.

$\mathrm{T}_{1}=$ control system first time constant.

$\mathrm{T}_{2}=$ control system second time constant .

$\mathrm{T}_{3}=$ control system third time constant.

$\mathrm{T}_{4}=$ water starting time constant (hydro turbine).

$\mathrm{T}_{5}=$ turbine time constant (hydro or thermal).

\section{Introduction}

Due to the restructuring of the Brazilian energy sector, when it comes to ways of generating electric energy, a concern with the distributed generation has been increasing in recent years.

In addition to the considerable increase in generation from the alcohol and sugar mills, it is also observed a tendency of growth of the independent generation in the National Electricity System. Most of these generators are connected to a local utility in the medium voltage system.

Thus, there is a need to better understand and study the influence of this trend in the electricity distribution networks. Among the main analysis, we highlight the monitoring of voltage levels and power factor at the Point of Common Coupling, after insertion of the Independent Generator.

To have greater control of such levels mentioned above, some types of synchronous machine excitation regulators are used, it is also necessary to control all parameters of these regulators so that the system does not reach instability or work in a not expected way. 
Alongside the current scenario and the search for alternatives to the problems that the restructuring electrical system can bring, in this article will be analyzed the parameters of a power factor regulator and its influence on the speed, power factor and rms voltage level of the synchronous machine in the PCC of a distributed generator.

\section{System modeling}

\section{A. Power Factor Regulator}

Power Factor Regulators, are nothing more than governors that act to maintain a pre-determined amount of power factor or reactive power at the synchronous machine terminals. It is important to highlight that, during transient periods, this control does not provide the increase of excitation needed to respond to a voltage drop in the system, this function is left to the voltage regulators [1].

Despite having distinct features, ie, the measured quantities being different, voltage and power factor regulators are very similar. Thus, one can use the models of voltage regulators for the power factor regulators, remembering that the measured quantity changes from voltage to power factor or reactive power. Figure 1 show the regulator model named type I, that will be used in this work, which is the most complete and recommended by the IEEE [2].

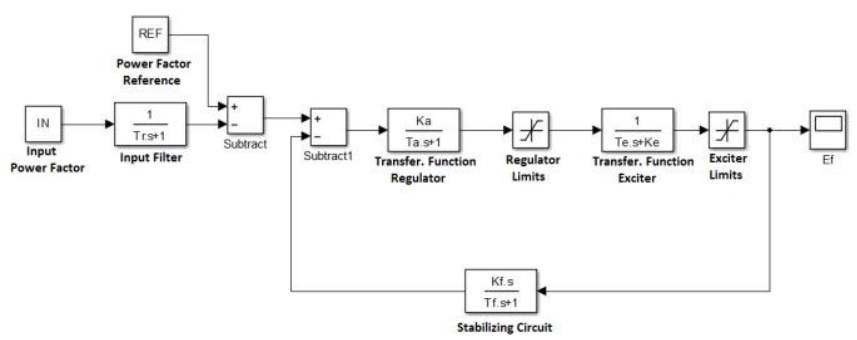

Fig. 1. Power Factor Regulator Model.

\section{B. Speed Governor}

The speed governor was built in a simple IEEE [2] model, that is frequently used in dynamics and transient stability studies. It is needed to remember that the influence of these governor parameters won't be studied in this paper.

Figure 2 shows the model of the speed governor used, that is already associated with a steam turbine (if $\mathrm{T}_{4}=0$ ) or a hydraulic turbine (if $\mathrm{T}_{4} \neq 0$ ).

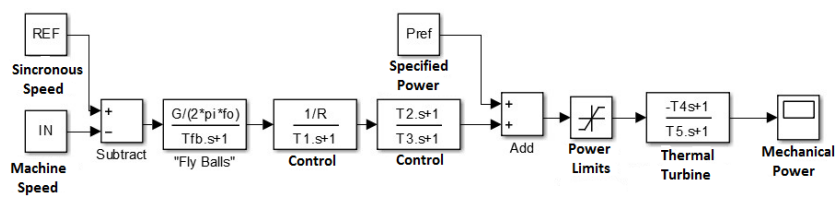

Fig. 2. Speed governor model.

\section{Electrical system}

Figure 3 shows a single line diagram of the system used for the connection of the Power Factor Regulator to later get the results of its application. Such diagram represents satisfactorily, an independent power producer connected to a larger system (Power Authority) [3].

In this system, the distribution network is connected at bus bar 3 (PCC) through a transformer, to the independent producer electrical system. To represent the independent power producer two synchronous generators were used (primary machines are steam turbines), a static and a variable load (motor), internal to the independent system. Thus, these internal generators can, besides meeting their loads, also supply power to the distribution network.

As can be seen in Figure 3, the distribution network comprises an ideal voltage source (infinite bus) which is connected to a transformer T1 through bus bar 1. This transformer $\mathrm{T} 1$ is connected to two distribution power lines, whose voltage at bus bar 2 is $13.8 \mathrm{kV}$. In bus bar 2, there is a three-phase capacitor bank and a three-phase load. Lines leaving bus bar 2, end at bus bar 3, which is then connected to the transformer T2. As in bus bar 2, to the bus bar 3 is also connected a three-phase capacitor bank and a three-phase load. This transformer T2 is used in the connection between the power utility and the independent producer system, which is connected to the bus bar 4 where the independent power producer generators are connected. Also at bus bar 4, another transformer T3 exists, that connects to bus bar 5, where are connected the loads of the independent power producer. All the independent producer synchronous machines parameters are in Table I, and is highlighted that such figures were obtained directly from the Brazilian maker WEG.

The modeling of the electrical system will not be addressed more thoroughly in this opportunity, since the focus of this article is the analysis of the parameters of the power factor regulator.

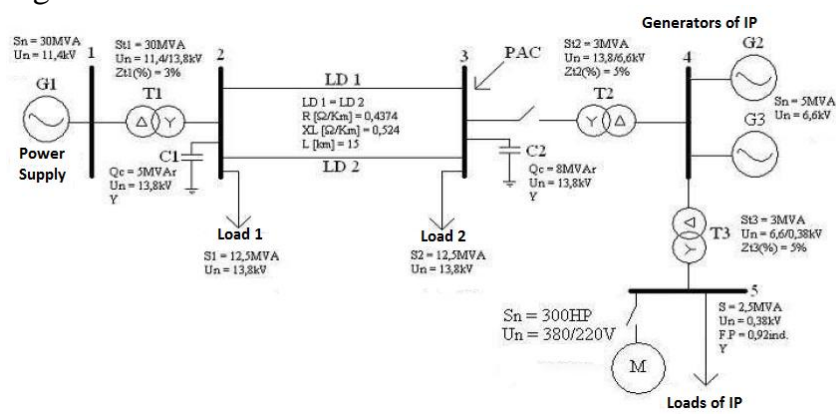

Fig. 3. Single line diagram of the electrical system simulated.

Table 1 - Independent Power Producer Synchronous Machine Parameters

\begin{tabular}{|c|c|}
\hline & \\
\hline$S n=5 \mathrm{MVA}$ & $\mathrm{X}_{\mathrm{o}}=0.046 \mathrm{pu}$ \\
\hline $\mathrm{Un}=6.6 \mathrm{kV}$ & $\mathrm{T}_{\mathrm{do}}^{\prime}=1.754 \mathrm{~s}$ \\
\hline $\mathrm{Ra}=0.004 \mathrm{pu}$ & $\mathrm{T}_{\mathrm{qo}}^{\prime}=0 \mathrm{~s}$ \\
\hline $\mathrm{X}_{\mathrm{L}}=0.1 \mathrm{pu}$ & $\mathrm{T}^{\prime \prime}{ }_{\mathrm{do}}=0.019 \mathrm{~s}$ \\
\hline $\mathrm{X}_{\mathrm{d}}=1.8 \mathrm{pu}$ & $T_{\text {qo }}^{\prime \prime}=0.164 \mathrm{~s}$ \\
\hline $\mathrm{X}_{\mathrm{q}}=1.793 \mathrm{pu}$ & $\mathrm{H}_{2}=1 \mathrm{~s} ; \mathrm{H}_{3}=2 \mathrm{~s}$ \\
\hline $\mathrm{X}_{\mathrm{d}}^{\prime}=0.166 \mathrm{pu}$ & $\mathrm{P}=4$ poles \\
\hline $\mathrm{X}_{\mathrm{q}}^{\prime}=0.98 \mathrm{pu}$ & $f=60 \mathrm{~Hz}$ \\
\hline $\mathrm{X}{ }_{\mathrm{d}}=0.119 \mathrm{pu}$ & $\omega=188.5 \mathrm{rad} / \mathrm{s}$ \\
\hline $\mathrm{X}{ }_{\mathrm{q}}=0.17 \mathrm{pu}$ & \\
\hline
\end{tabular}

\section{Case studies}

Similar to the studies made here, were carried out in [4], but here it is used the Simulink tool of Matlab and parameters of 
a Voltage Regulator were analyzed. In this work, was used the simulations involving the complete electrical system using simulations from ATP-EMTP, and the parameters analyzed were of a Power Factor Regulator, which despite having a very similar behavior with Voltage Regulator, is distinct in the case of measured quantities.

In this study, the influence of stabilizer $\left(\mathrm{K}_{\mathrm{f}}\right.$ and $\left.\mathrm{T}_{\mathrm{f}}\right)$, the exciter $\left(\mathrm{T}_{\mathrm{e}}\right)$ and the regulator $\left(\mathrm{K}_{\mathrm{a}}\right.$ and $\left.\mathrm{T}_{\mathrm{a}}\right)$ parameters will be observed. Noting that the initial values of each parameter are shown in Table 2 [9], and such amounts are varied one by one by by a range determined by the author (with the previous study of the best values to be simulated) and therefore, appropriate analysis can be made. It is noteworthy that the gain of the exciter $\left(\mathrm{K}_{\mathrm{e}}\right)$ will not be analyzed, because its influence is the same as the regulator gain $\left(\mathrm{K}_{\mathrm{a}}\right)$, by just making simulations with one of them.

Table 2 - Initial values for the Power Factor Regulator parameters.

\begin{tabular}{|c|c|c|c|}
\hline Parameter & Value & Parameter & Value \\
\hline $\mathrm{K}_{\mathrm{a}}$ & 500 & $\mathrm{Ta}$ & 0.1 \\
\hline $\mathrm{K}_{\mathrm{f}}$ & 0.8 & $\mathrm{Tf}$ & 0.1 \\
\hline $\mathrm{K}_{\mathrm{e}}$ & 1 & $\mathrm{Te}$ & 0.05 \\
\hline $\begin{array}{c}\text { Minimum Limit } \\
\text { Regulator }\end{array}$ & 0 & $\begin{array}{c}\text { Maximum Limit } \\
\text { Regulator }\end{array}$ & 1.6 \\
\hline $\begin{array}{c}\text { Minimum Limit } \\
\text { Exciter }\end{array}$ & 0 & $\begin{array}{c}\text { Maximum Limit } \\
\text { Exciter }\end{array}$ & 500 \\
\hline
\end{tabular}

\section{A. Influence of parameters on RMS Voltage at the PCC.}

For a better analysis of the results, is required a greater concern with the quality of energy that is being delivered to the distribution network. Therefore, in light of the Module 8 PRODIST - ANEEL [5], and also of some technical requirements of Brazilian Power Utilities [6][7][8], it is concluded that the rms voltage at the point of common coupling, should be between 0.95 and $1.05 \mathrm{pu}$. Since in this case the base rms voltage is approximately $7,967.4 \mathrm{~V}$, this should have values between $7,569 \mathrm{~V}$ and $8,365.8 \mathrm{~V}$ for which technical standards are met.

Thus it is possible to do a well situated analysis of each Regulator parameter.

$$
\text { i) “ } K_{a} \text { ” parameter. }
$$

Through Figure 4, can be seen that in terms of overshoot and stabilization time, there is no considerable influence of the gain $K_{a}$, however, when it comes to magnitude of rms voltage in steady state, this parameter has a proportional influence, that is, when it increases there is an increase in the rms voltage.

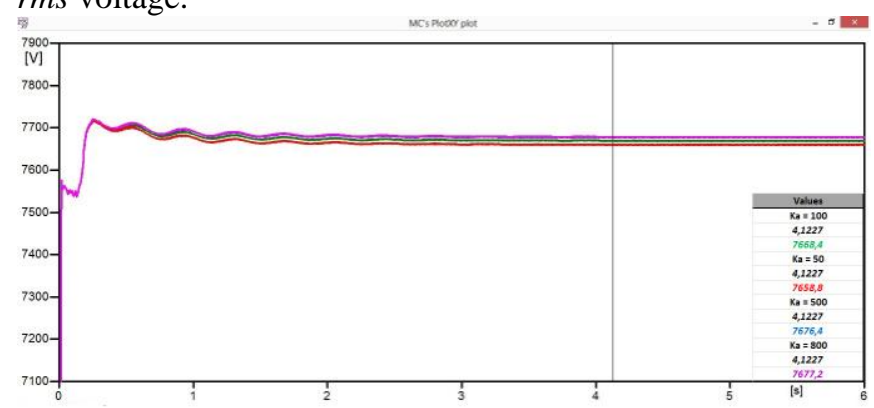

Fig. 4. $R M S$ voltage behavior at the $\mathrm{PCC}$ with " $\mathrm{K}_{\mathrm{a}}$ " parameter variation.
ii) “ $T_{a}$ ” parameter.

Figure 5 shows that the influence of time constant is similar to the influence of gain $K_{a}$, because this also only significantly changes the magnitude of $r m s$ voltage in steady state.

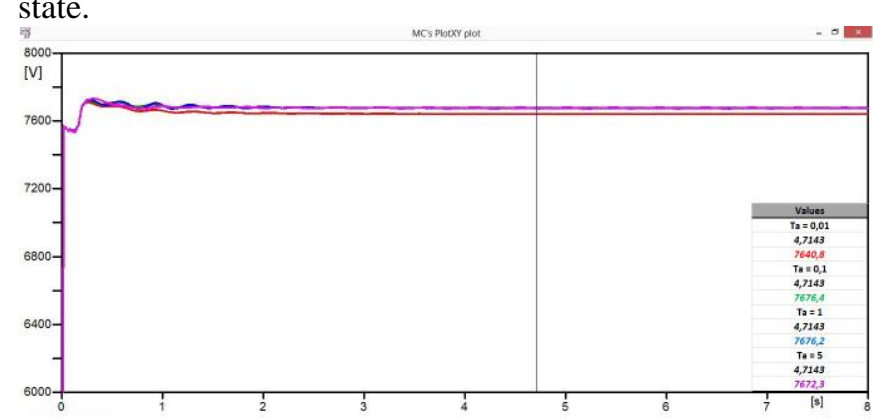

Fig 5. RMS voltage behavior at the PCC with "T" " parame variation.

iii) “ $K_{f}$ ” parameter.

An interesting fact to be noted in Figure 6, is that the gain variation $K_{f}$ directly influences the $r m s$ voltage stabilization time, because as this gain is increased, has resulted in a faster stabilization time of voltage (in the case that $\mathrm{K}_{\mathrm{f}}=0.08$ voltage stabilization was not complete). Furthermore, it is also possible to note that the voltage overshoot is higher for smaller values of this gain.

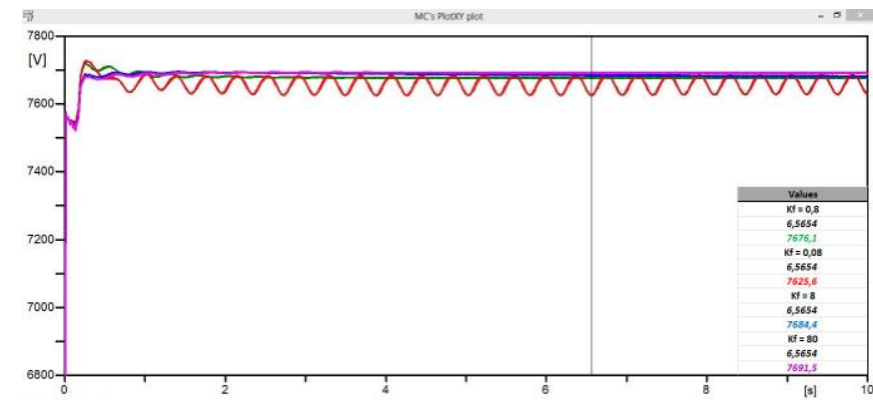

Fig. 6. $R M S$ voltage behavior at the PCC with " $\mathrm{K}_{\mathrm{f}}$ " parameter variation.

iv) “ $T_{f}$ ” Parameter.

Through observation of Figure 7, one notes that the time constant $T_{f}$ has similar influence with the $K_{f}$ gain (in terms of settling time), but in this case as the constant $T_{f}$ increases a longer stabilization time is observed and consequently greater instability in the rms voltage in the PCC. 


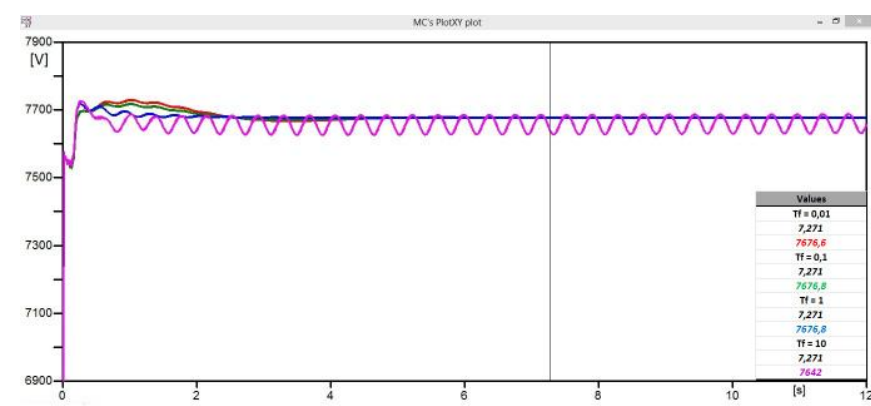

Fig. 7. $R M S$ voltage behavior at the $\mathrm{PCC}$ with " $\mathrm{T}_{\mathrm{f}}$ " parameter variation.

\section{v) “ $T_{e}$ ” Parameter.}

With the behavior shown in Figure 8, it follows that the influence of the time constant $T_{e}$ is merely connected to the overshoot of the response of rms voltage, since the more it decreases the value of the constant, more the rms voltage response overshoot grows.

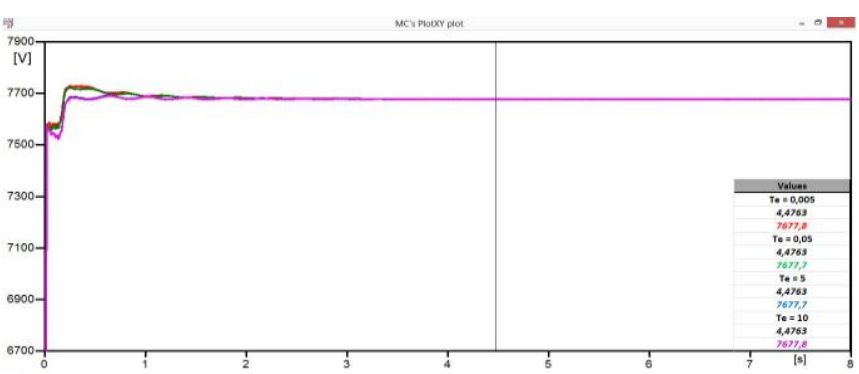

Fig. 8. RMS voltage behavior at the $\mathrm{PCC}$ with " $\mathrm{T}_{\mathrm{e}}$ " parameter variation.

\section{B. Influence of the parameters in PCC Power Factor.}

More precisely, the PRODIST [5] technical standard, stipulates the allowable limits for the power factor at the point of common coupling. In this case these limits must be between 1 and 0.92 inductive or capacitive. In this case, it is set as a reference power factor the value of 0.95 inductive. With these data, we can then carry out the study of the influence of each parameter of the Regulator.

\section{i) “ $K_{a}$ ” Parameter}

Figure 9 shows that the gain $K_{a}$ has a fundamental role in the magnitude of the power factor in steady state, since that at the extent that this gain increases there is also an increase in the power factor at the PCC in steady state. On the other hand, considering overshoot and settling time, this parameter is not so significant.

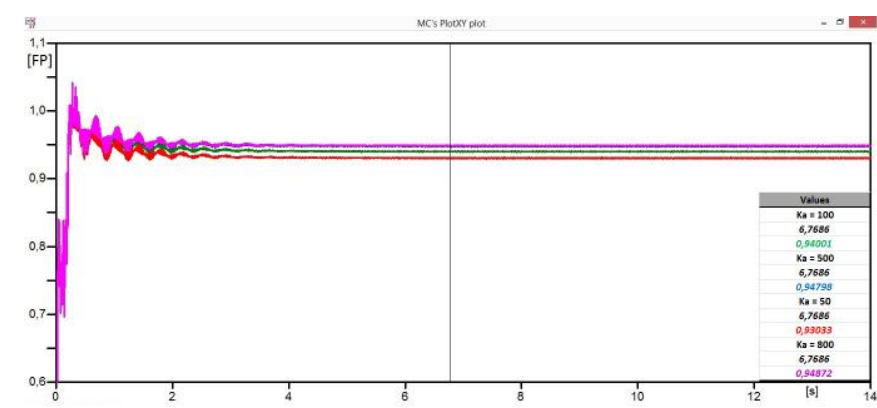

Fig. 9. Behavior of the Power Factor at PCC with changes in $K_{a}$ parameter.

ii) “ $T_{a}$ ” Parameter

The influence of the time constant $T_{a}$ is quite similar to the gain $K_{a}$, since this also considerably modifies the power factor in steady state, or rather, as it decreases the value of this constant, lower values of power factor will be observed at the PCC. This can be seen from Figure 10, however, it is seen that this value also has an impact in terms of overshoot and settling time, since the larger the time constant, the larger the overshoot and settling time of the response .

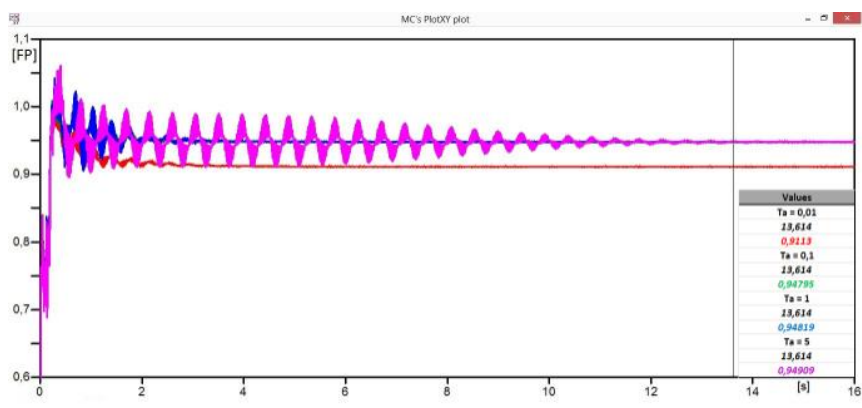

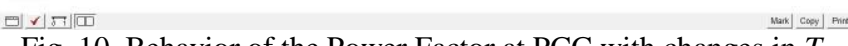

Fig. 10. Behavior of the Power Factor at PCC with changes in $T_{a}$ parameter.

iii) “ $K_{f}$ ” Parameter

From Figure 11, we see that besides the notable influence on the magnitude of the power factor in steady state, the gain $K_{f}$ also greatly influences the stability of the control of this power factor, since for very small values of this gain (eg $K_{f}=$ 0.08 ) control enters in the instability region, ie oscillates continuously.

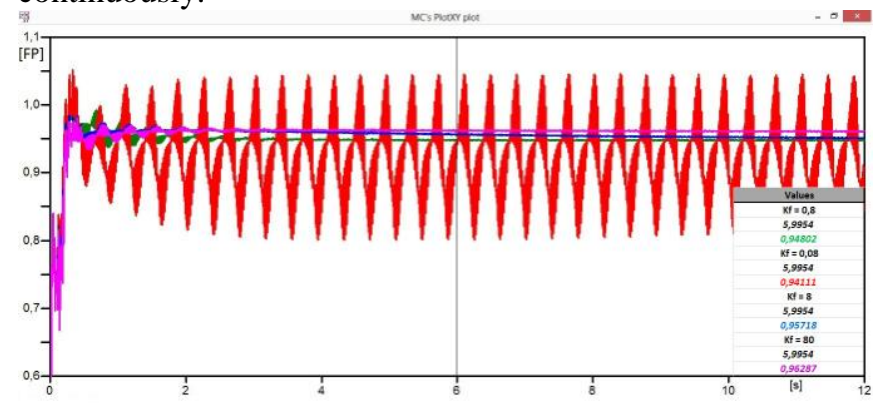

Fig. 11. Behavior of the Power Factor at PCC with changes in $K_{f}$ parameter. 


\section{iv) "Tf" Parameter}

The influence of this time constant is quite similar to the gain $K_{f}$, as in Figure 12, this constant also influences the control system stability. However, for this parameter is evident also an influence in terms of overshoot, for the increase of the constant value the overshoot decreases and this decrease is combined with an increase of the control instability.

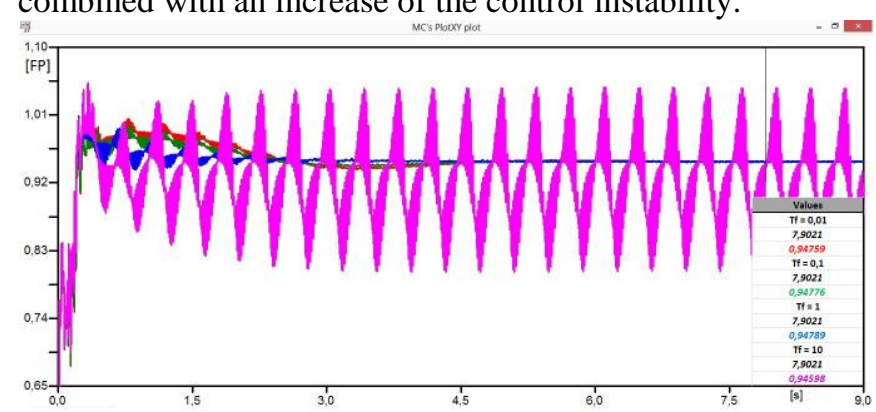

피 15 . i) “ $T_{e}$ ” Parameter parameter.

With the behavior shown in Figure 13, it can be said that the influence of the time constant $T_{e}$ is related only to the overshoot of the response since the magnitudes and stabilization times are quite similar for all the different values simulated. Thus, it is concluded that the lower the value of this parameter, the higher the observed overshoot.

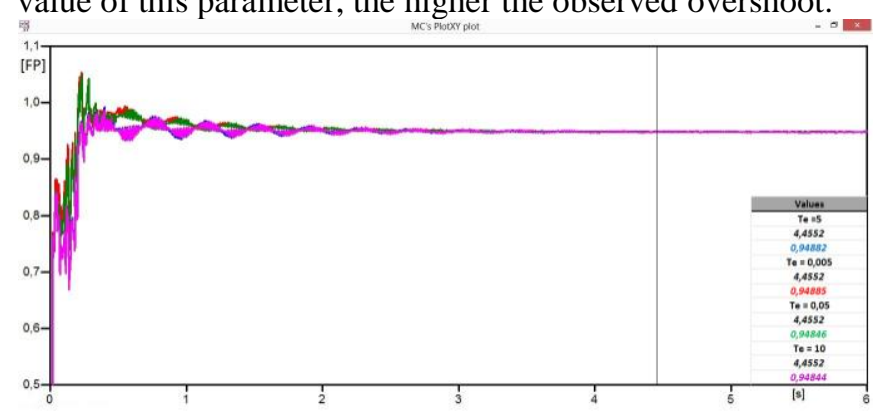

Fig. 13. Behavior of the Power Factor at PCC with changes in $T_{e}$ parameter.

\section{Influence of parameters in the speed of the synchronous machine.}

With the presence of the Speed Regulator connected to the synchronous machine is expected to obtain values very close to $188.5 \mathrm{rad} / \mathrm{s}(60 \mathrm{~Hz})$ in steady state. Therefore, unless the parameters of the Power Factor Regulator has influence so there is a complete instability of the speed of the machine, which will be studied in this article will point the main focus in the transient regime of operation of the synchronous machine, in terms of overshoot and settling time of the speed response.

It is noteworthy also, related to power quality, the frequency variation permitted on the network varies between $59.9 \mathrm{~Hz}$ and $60.1 \mathrm{~Hz}$ [5]. Moreover, such variations in the speed of the synchronous machine, can result in equipment damage if they have great time length [10].

\section{i) “ $K_{a}$ ” Parameter}

With the analysis of Figure 14, one easily concludes that the gain $K_{a}$ has influence only in the overshoot of the speed response in the synchronous machine, but such influence is almost negligible. In terms of settling time of the response, we note that this parameter does not bring any influence.

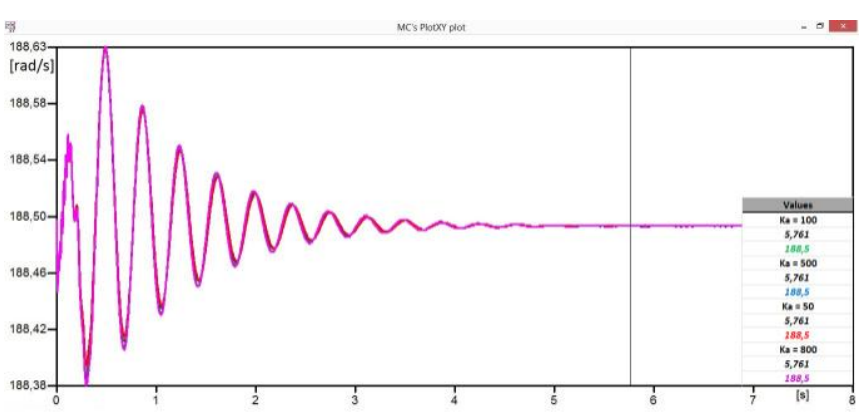

Fig. 14. Behavior of the synchronous machine speed with changes in $K_{a}$ parameter.

\section{i) " $T_{a}$ ” Parameter}

In this case, examining Figure 15, it is observed that decreasing the time constant $T_{a}$, results in a drastic decrease in the overshoot of the speed response. Moreover, it is remarkable for constant values greater than 1 , that there is a considerable increase in the settling time of the speed of the machine.

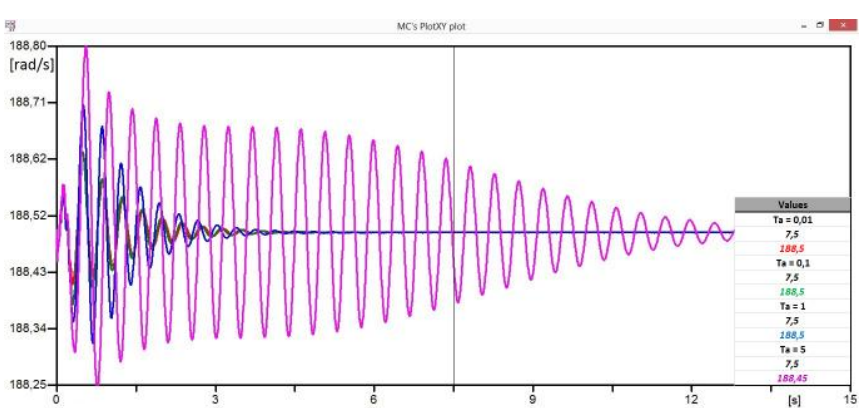

r I

Fig. 15. Behavior of the synchronous machine speed with changes in $T_{a}$ parameter.

\section{ii) “ $K f$ ” Parameter}

Figure 16 shows the variation of the time constant $K_{f}$, that significantly influences the overshoot of the speed response, because increasing the value of this constant the overshoot is decreased. An important observation in this simulation is that if this parameter has very small values, the machine may enter instability (as seen with $K_{f}=0.08$ ) and with that potential damage may be caused to the synchronous machine. 


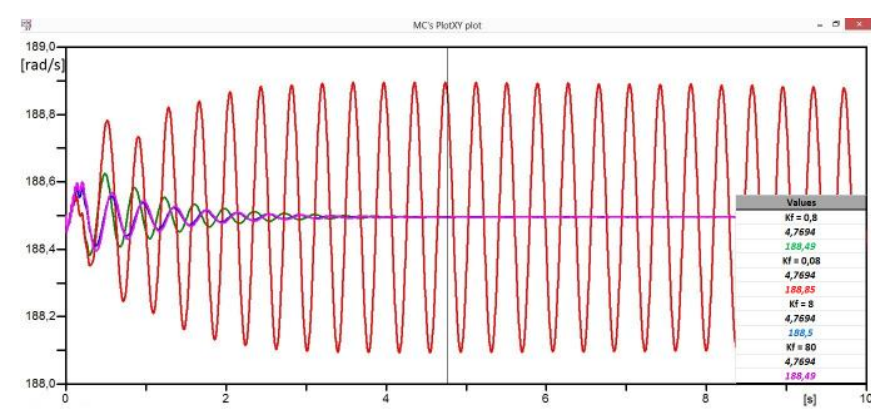

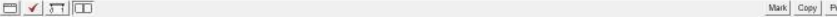

Fig. 16. Behavior of the synchronous machine speed with changes in $K_{f}$ parameter.

iii) "Tf” Parameter

With the analysis of Figure 17 it is concluded that the influence of time constant $T_{f}$ is quite similar to the influence of the gain $K_{f}$, but are reversed. Since in this case when $T_{f}$ greatly increases, the system tends to instability and with low values for this parameter, we have responses with less overshoot.

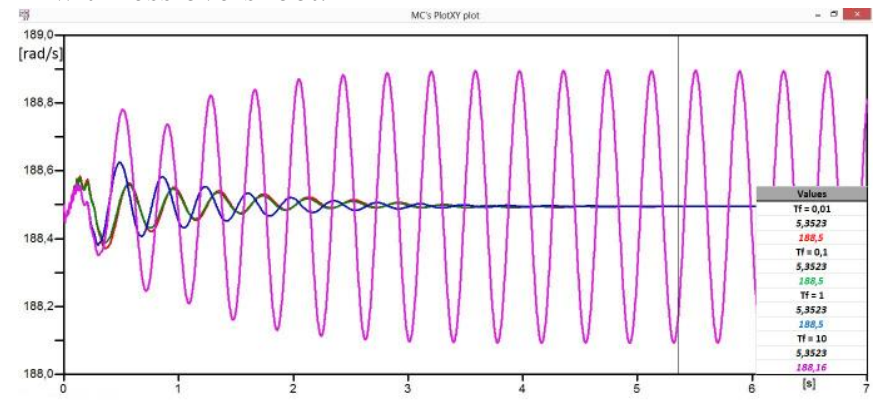

Fig. 17. Behavior of the synchronous machine speed with changes in $T_{f}$ parameter.

iv) “Te” Parameter

By the simulations shown in Figure 18, this parameter had significant influences both in the response overshoot as the stabilization time, since it is noted lower stabilization times and overshoot for smaller values of the time constant $T_{e}$

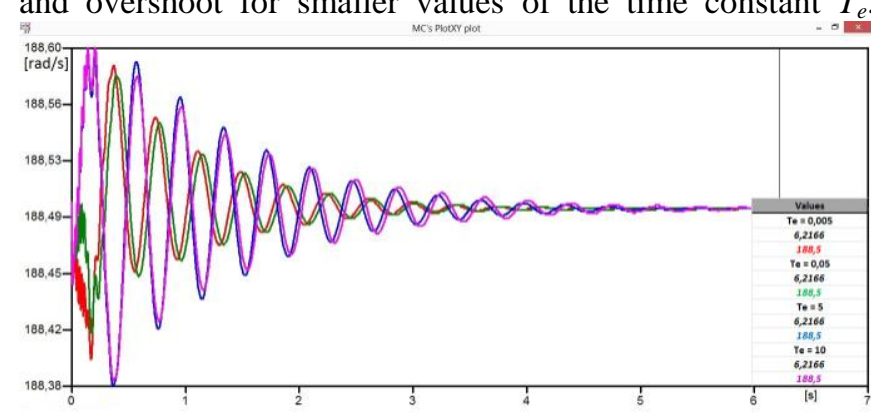

Fig. 18. Behavior of the synchronous machine speed with changes in $T_{e}$ parameter.

\section{Conclusions}

This article presents in a well-defined way, the influences caused by each of the main parameters in the Regulator
Power Factor model under study. This research provides an effective and accurate parameterization on the electrical system presented.

It is also evident that for some of the simulated values, there was a technical infringement regarding the power quality in the PCC standards, especially regarding power factor and speed of the synchronous machine. From this fact, it is highlighted the importance of studies like the one conducted here.

\section{Acknowledgement}

The authors acknowledge the financial support from the Universidade Federal do Triângulo Mineiro - UFTM and the Department of Electrical Engineering - DEE.

\section{References}

[1] IEEE Std. 421.5-2005, IEEE Recommended Practice for Excitation System Models for Power System Stability Studies, 2005.

[2] G. C. Guimarães, Computer Methods for Transient Stability Analysis of Isolated Power Generation Systems with Special Reference to Prime Mover and Induction Motor Modelling, $\mathrm{PhD}$ Thesis, University of Aberdeen, 1990.

[3] F. A. M. Moura, Distributed Generation - Impacts and Contributions to the Power Quality and Dynamic of Electrical Systems - An Analysis by ATP-EMTP, Doctoral Thesis, Universidade Federal de Uberlândia, Uberlândia, MG, Brazil, 2011. \{In Portuguese $\}$

[4] L. M. Peres, Studies of the Dynamic Performance of Synchronous Generators of Independent Producers in Distributed Generation Systems via ATPDraw, MSc Dissertation, Universidade Federal de Uberlândia, Uberlândia, MG, Brazil, 2013. \{In Portuguese $\}$

[5] PRODIST - Procedures for Electricity Distribution in the National Electric System, Module 8, Quality of Electricity, 2012. Available at: http://tinyurl.com/m3974dg . Accessed in May 6, 2014. \{In Portuguese\}

[6] CEMIG - Requirements for Connecting Independent Power Producers to CEMIG Distribution System - Medium Voltage Connection, 2011. Available at: http://tinyurl.com/qjv47f4 . Accessed in May 15, 2014. \{In Portuguese $\}$

[7] COPEL - Technical requirements for the connection of generation in parallel with the COPEL electrical system, 2006. Available at: http://tinyurl.com/m6jwghq. Accessed in: May 25, 2014. \{In Portuguese $\}$

[8] CEMAT - Requirements for access and connection of distributed generation to the CEMAT distribution system, 2013. Available at: http://tinyurl.com/ng3u4o6. Accessed in May 01, 2014 . $\{$ In Portuguese $\}$

[9] M. Resener; R. H. Salim and A.S.Bretas, Evaluation of the Impact of Excitation Controllers in Transient Stability of Synchronous Generators connected in Distribution Systems. SBSE2012 - Brazilian Symposium on Electrical Systems, Accessed in August 25, 2014, http://tinyurl.com/pfktb24. \{In Portuguese $\}$

[10] F. A. M. Moura, J. R. Camacho, L. R. Chaves and G. C. Guimarães, Grid Integration of Renewable Sources in the Distribution Network: An Analysis Through ATP-EMTP, Conference on Innovative Smart Grid Technologies (ISGT), 2012 IEEE PES, doi:10.1109/ISGT.2012.6175650. 